\title{
BMJ Open Rationale and design of platelet transfusions in haematopoietic stem cell transplantation: the PATH pilot study
}

\author{
Jason Tay, ${ }^{1,2,3}$ David Allan, ${ }^{2}$ Sara Beattie, ${ }^{4}$ Christopher Bredeson, ${ }^{2,3}$ \\ Dean Fergusson, ${ }^{2,3}$ Dawn Maze, ${ }^{5}$ Mitchell Sabloff, ${ }^{2}$ Kednapa Thavorn, ${ }^{3}$ \\ Alan Tinmouth ${ }^{2,3}$
}

To cite: Tay J, Allan D, Beattie S, et al. Rationale and design of platelet transfusions in haematopoietic stem cell transplantation: the PATH pilot study. BMJ Open 2016;6:e013483. doi:10.1136/bmjopen-2016013483

- Prepublication history for this paper is available online. To view these files please visit the journal online (http://dx.doi.org/10.1136/ bmjopen-2016-013483).

Received 14 July 2016 Revised 2 September 2016 Accepted 15 September 2016

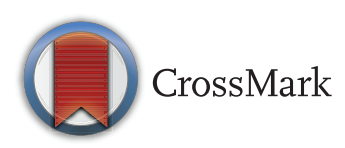

${ }^{1}$ Department of Medicine, University of Calgary, Calgary, Alberta, Canada ${ }^{2}$ Department of Medicine, University of Ottawa, Ottawa, Ontario, Canada

${ }^{3}$ Clinical Epidemiology Program, Ottawa Hospital Research Institute, Ottawa, Ontario, Canada

${ }^{4}$ Department of Psychosocial Oncology, Tom Baker Cancer Centre, Calgary, Alberta, Canada

${ }^{5}$ Department of Medicine, University of Toronto

Correspondence to Dr Jason Tay; jason.tay@ahs.ca

\section{ABSTRACT}

Introduction: In patients with transient thrombocytopenia being treated with high-dose chemotherapy followed by stem cell rescuehaematopoietic stem cell transplantation (HSCT), prophylactic transfusions are standard therapy to prevent bleeding. However, a recent multicentre trial suggests that prophylactic platelet transfusions in HSCT may not be necessary. Additionally, the potential overuse of platelet products places a burden on a scarce healthcare resource. Moreover, the benefit of prophylactic platelet transfusions to prevent clinically relevant haemorrhage is debatable. Current randomised data compare different thresholds for administering prophylactic platelets or prophylactic versus therapeutic platelet transfusions. An alternative strategy involves prescribing prophylactic antifibrinolytic agents such as tranexamic acid to prevent bleeding.

Methods and analysis: This report describes the design of an open-labelled randomised pilot study comparing the prophylactic use of oral tranexamic acid with platelet transfusions in the setting of autologous HSCT. In 3-5 centres, 100 patients undergoing autologous HSCT will be randomly assigned to either a prophylactic tranexamic acid or prophylactic platelets bleeding prevention strategy-based daily platelet values up to 30 days post-transplant. The study will be stratified by centre and type of transplant. The primary goal is to demonstrate study feasibility while collecting clinical outcomes on (1) WHO and Bleeding Severity Measurement Scale (BSMS), (2) transplant-related mortality, (3) quality of life, (4) length of hospital stay, (5) intensive care unit admission rates, (6) Bearman toxicity scores, (7) incidence of infections, (8) transfusion requirements, (9) adverse reactions and (10) economic analyses.

Ethics and dissemination: This study is funded by a peer-reviewed grant from the Canadian Institutes of Health Research (201 503) and is registered on Clinicaltrials.gov NCT02650791. It has been approved by the Ottawa Health Science Network Research Ethics Board. Study results will presented at national and international conferences. Importantly, the results of this trial will inform the feasibility and conduct of a larger study.

\section{Strengths and limitations of this study}

- Pilot randomised study (Vanguard design) to better assure feasibility and inform the design of a larger randomised study in recipients of autologous haematopoietic stem cell transplantation.

- First study in autologous haematopoietic stem cell transplantation to evaluate a strategy of prophylactic tranexamic acid with prophylactic platelet transfusions to prevent bleeding.

- First prospective study to concurrently use two bleeding scales-WHO and Bleeding Severity Measurement Scale (BSMS) to better appreciate clinically relevant bleeding.

- The trial will collect health-related quality of life data using a variety of validated scales within the context of bleeding risk and autologous haematopoietic stem cell transplantation.

- A limitation of this study is the absence of a 'third' control arm, where participants only receive therapeutic platelets (without prophylactic platelets or prophylactic tranexamic acid.

Trial registration number: NCT02650791; Pre-results.

\section{INTRODUCTION}

Background and rationale

What is the problem to be addressed?

In Canada, over 1500 autologous haematopoietic stem cell transplantations (ASCT) are performed annually for haematological malignancies (personal communication between Dr Dawn Maze (Sheppard) and Dr $\mathrm{K}$ Paulsen, Canadian blood and marrow transplant group registry, 2015). It is currently a standard practice to provide prophylactic transfusion of platelets to prevent bleeding when the daily measured platelet count is $<10 \times 10^{9} / \mathrm{L}^{1-4}$ A patient may require 
up to six adult platelet doses during the post-transplant period. ${ }^{5}$ However, the true benefit of prophylactic platelet transfusions in the ASCT setting is unclear and has been called into question by several recent studies. ${ }^{6-8}$

Prophylactic platelet transfusions may not only be unnecessary, they may be detrimental to the patient. Among blood products, platelet transfusions are associated with the highest risk of infectious and noninfectious complications: this would include bacterial infections and allergic/febrile reactions (table 1). ${ }^{9-12}$

Moreover, the potential overuse of platelet products places a significant burden on a scarce healthcare resource that is provided through volunteer donations. This concern is further highlighted by the two recent 'alert' warnings of significant platelet shortages or potential shortages either regionally or nationally issued by the Canadian Blood Services (personal communication, R Trifulnov, Canadian Blood Services 2015).

An alternative strategy to prevent bleeding and reduce the need for platelet transfusions involves administering

Table 1 Platelet transfusion risks*

\begin{tabular}{|c|c|}
\hline Risk of event & Event \\
\hline 1 in 20 & $\begin{array}{l}\text { Febrile non-haemolytic transfusion } \\
\text { reaction per pool of platelets }\end{array}$ \\
\hline 1 in 100 & Minor allergic reactions (urticaria) \\
\hline 1 in 300 & $\begin{array}{l}\text { Febrile non-haemolytic transfusion } \\
\text { reaction per unit of RBC ( } 1 \text { 'donor } \\
\text { exposure') }\end{array}$ \\
\hline 1 in 700 & $\begin{array}{l}\text { Transfusion-associated circulatory } \\
\text { overload per transfusion episode }\end{array}$ \\
\hline 1 in 7000 & Delayed haemolytic transfusion reaction \\
\hline 1 in 10000 & TRALI \\
\hline 1 in 10000 & $\begin{array}{l}\text { Symptomatic bacterial sepsis per pool of } \\
\text { platelets }\end{array}$ \\
\hline 1 in 40000 & $\begin{array}{l}\text { ABO-incompatible transfusion per RBC } \\
\text { transfusion episode }\end{array}$ \\
\hline 1 in 40000 & $\begin{array}{l}\text { Serious allergic reaction per unit of } \\
\text { component }\end{array}$ \\
\hline 1 in 60000 & $\begin{array}{l}\text { Death from bacterial sepsis per pool of } \\
\text { platelets }\end{array}$ \\
\hline 1 in 153000 & $\begin{array}{l}\text { Death from bacterial sepsis per pool of } \\
\text { platelets }\end{array}$ \\
\hline 1 in 250000 & $\begin{array}{l}\text { Symptomatic bacterial sepsis per unit of } \\
\text { RBC }\end{array}$ \\
\hline 1 in 500000 & $\begin{array}{l}\text { Death from bacterial sepsis per unit of } \\
\text { RBC }\end{array}$ \\
\hline$<1$ in 1000000 & Transmission of West Nile virus \\
\hline 1 in 2300000 & $\begin{array}{l}\text { Transmission of hepatitis } \mathrm{C} \text { virus per unit } \\
\text { of component }\end{array}$ \\
\hline 1 in 4000000 & $\begin{array}{l}\text { Transmission of Chagas disease per unit } \\
\text { of component }\end{array}$ \\
\hline 1 in 4300000 & $\begin{array}{l}\text { Transmission of HTLV per unit of } \\
\text { component }\end{array}$ \\
\hline 1 in 7800000 & $\begin{array}{l}\text { Transmission of HIV per unit of } \\
\text { component }\end{array}$ \\
\hline
\end{tabular}

*http://ibta.ir/en/wp-content/uploads/111_Bloody-Easy_3rd-1.pdf. HTLV, human T-lymphotropic virus; TRALI, transfusion-related acute lung injury; RBC, red blood cell. tranexamic acid, an oral antifibrinolytic agent to stabilise blood clots and reduce bleeding. ${ }^{13}$ Tranexamic acid is safe and effective in many clinical scenarios, ${ }^{14}{ }^{15}$ and may be a reasonable alternative for prophylactic platelet transfusions. In the setting of ASCT, tranexamic acid may reduce bleeding and further enhance the strategy of therapeutic platelet transfusions where platelets are administered only in the event of active bleeding symptoms.

The effect of prophylactic platelet transfusions and tranexamic acid on clinical, quality of life (QoL) and economic outcomes in patients receiving ASCT is unknown. Our overarching goal is to perform a randomised controlled trial to determine whether a strategy of prophylactic tranexamic acid (with therapeutic platelet transfusions) is safe and effective compared to prophylactic platelet transfusions in patients undergoing ASCT. Before conducting a larger trial, we first propose a pilot randomised controlled trial to determine the feasibility of such a study.

\section{Why is a trial needed now?}

The evidence supporting the use of prophylactic platelets to prevent bleeding in ASCT is weak and platelets remain the scarcest blood resource with the highest complication rate of all blood products. Patients undergoing transplant represent an important proportion of patients receiving platelet transfusions and there is a need to identify an alternative strategy to prevent and control bleeding in this high-risk population. Clinical trials evaluating the effectiveness of platelet transfusions in patients with haematological malignancies are heterogeneous and have included patients being treated with a variety of modalities, including high-dose chemotherapy, autologous transplantation and allogeneic transplantation. They have examined different prophylactic platelet transfusion thresholds, different platelet doses and a solely therapeutic platelet transfusion strategy (ie, no tranexamic acid or other antifibrinolytic agent). In the latter circumstance, a therapeutic platelet transfusion strategy did not appear to increase bleeding in subgroup analyses of patients undergoing ASCT. ${ }^{6}{ }^{8}$ A strategy of prophylactic tranexamic acid combined with therapeutic platelet transfusions may reduce bleeding, platelet transfusions and the adverse consequences associated with platelet transfusions.

\section{Platelet transfusion requirements in autologous stem cell transplantation}

In Canada, over 1500 ASCTs are performed annually (personal communication between Dr Dawn Maze (Sheppard) and Dr K Paulsen, Canadian blood and marrow transplant group registry, 2015). A patient undergoing ASCT typically receives 1-6 adult platelet doses in the post-transplant period. ${ }^{8}{ }^{16-20}$ All adult transplant centres in Canada routinely prescribe prophylactic platelet transfusions when the daily measured platelet count is $<10 \times 10^{9} / \mathrm{L}$ (Personal communication between Dr. Dawn(Maze) with Dr. C Bredeson. Bredeson C. 
President of Canadian blood and marrow transplant group. In: Sheppard D, ed, 2015). Indeed, this is the practice at our centre, where an average of six adult platelet doses are transfused in the first 60 days following transplant. $^{5}$

\section{Are prophylactic platelet transfusions beneficial?}

The practice of prophylactic platelet transfusions began following the publication of an observational study in patients with acute leukaemia in the early 1960s that observed an increase in the number of days with bleeding with worsening thrombocytopenia. ${ }^{21}$ However, the onset of major bleeding was not clearly related to a specific platelet threshold. Moreover, a review of 3000 thrombocytopenic adult patients with oncological diseases over a 10-year period, did not demonstrate a correlation between platelet count and the risk of haemorrhage. ${ }^{22}$ Patient-specific factors, including recent bleeding and recipients of haematopoietic stem cell transplantation (HSCT), rather than platelet counts were associated with increased risk and severity of bleeding. Counterintuitively, a study of platelet count recovery following HSCT reported that most clinically important bleeding events occurred when the morning platelet count was $>20 \times 10^{9} / \mathrm{L}^{25}$ Finally, a review of all case reports of severe intracranial haemorrhage from studies of prophylactic platelet transfusions found no association between the occurrence of major (intracranial) bleeding and the platelet count just prior to bleeding. ${ }^{26}$

\section{Therapeutic versus prophylactic platelet transfusion \\ strategies: randomised controlled trials}

Despite the fact that administering prophylactic platelet transfusions to patients with severe thrombocytopenia is a common practice, in several clinical settings this practice is poorly supported by evidence. The best evidence for a prophylactic platelet strategy is in patients with acute leukaemia. ${ }^{6}$ It has been proposed that patients undergoing ASCT and those with chronic, stable thrombocytopenia ${ }^{825}$ may be effectively managed with a therapeutic transfusion strategy, thus minimising the need for unnecessary transfusions and their associated risks.

Until recently, the only evidence to support a prophylactic platelet transfusion strategy rather than a therapeutic strategy resulted from three small randomised trials in patients undergoing high-dose therapy for acute leukaemia in the 1970 s. $^{26-28}$ In two studies, bleeding events were lower in patients receiving prophylactic platelet transfusions ${ }^{26}{ }^{27}$ and in two studies, platelet transfusions were reported to be decreased in patients receiving therapeutic transfusions. ${ }^{27}{ }^{28}$ However, it was difficult to draw any definitive conclusions from these studies as they are older, included small numbers of patients who received aspirin therapy as an antipyretic and suffered from various methodological limitations.

Recently, two large randomised controlled trials comparing prophylactic and therapeutic platelet transfusion strategies in patients with haematological malignancies have been published. First, Wandt et al randomised 396 patients undergoing chemotherapy for acute myeloid leukaemia or ASCT, to either prophylactic or therapeutic platelet transfusions. Grade 2 (moderate bleeding not requiring transfusion) or greater bleeding using a modified WHO scale occurred in $65(19 \%)$ patients in the prophylactic group and $127(42 \%)$ patients in the therapeutic group $(\mathrm{p}<0.0001) .{ }^{8}$ Additionally, there was increase in grade 4 bleeding-13 (7\%) vs 4 (2\%), $\mathrm{p}=0.0095$, in patients with acute leukaemia in the therapeutic arm. In contrast, in patients undergoing ASCT there was no difference in incidence of grade 3 or 4 bleeding events observed in either arm. The mean number of platelet transfusions was reduced by $33.5 \%$ $(p<0.0001)$ in the therapeutic arm. The authors concluded that prophylactic platelet transfusions should remain the standard of care for patients undergoing treatment for acute leukaemia, but a therapeutic strategy could be possibly adopted for patients undergoing ASCT.

Similarly, the TOPPS investigators ${ }^{6}$ randomised patients with a variety of haematological malignancies undergoing chemotherapy, autologous or allogeneic stem cell transplantation to either a prophylactic or therapeutic platelet transfusion strategy. The primary end point, WHO grade 2 bleeding or greater, occurred in $151(50 \%)$ patients in the therapeutic group and 128 $(43 \%)$ patients in the prophylactic group $(\mathrm{p}=0.06$ for non-inferiority). In a predefined subgroup analysis of patients undergoing ASCT, there was no difference in grade 2 bleeding or higher between the groups-99/ $210(47 \%)$ patients in the therapeutic group versus 95/ $210(45 \%)$ patients in the prophylactic group. For the entire study population, fewer patients in the therapeutic group received platelet transfusions-176 (59\%) vs $266(89 \%), \mathrm{p}<0.001$. The authors concluded that prophylactic platelet transfusions should remain the standard of care, but identified that a therapeutic strategy in the ASCT setting warrants further investigation. It is notable that neither the Wandt et al nor the TOPPS trial were adequately powered to evaluate bleeding risk in the ASCT setting.

\section{Are platelet transfusions harmful?}

Among blood products, platelets are associated with the highest risk of transfusion-related infectious and noninfectious complications. ${ }^{9-12}$ Some complications associated with platelet transfusions include fevers, rigors, acute lung injury, volume overload, haemolysis, platelet refractoriness, bacterial contamination and rarely, viral transmission. Though some of these reactions are mild, they often require discontinuation of the transfusion and another transfusion at a later time. This adds stress to the limited platelet inventory, and can also increase patient length of stay, and increase patient anxiety. There is also an emerging body of literature that suggests that transfusions may modulate immunological 
function and adversely affect treatment outcome in haematological malignancies. In a study of patients with acute leukaemia, increased platelet transfusions during induction was associated with decreased survival ${ }^{29}$ and we have recently demonstrated an association between transplant-related morbidity and mortality with the number of platelet transfusions. ${ }^{5}$

\section{Therapeutic versus prophylactic platelet transfusion} strategies in patients undergoing autologous haematopoietic stem cell transplantation

As described above, the results of two recent randomised controlled trials lead us to question the value of prophylactic platelet transfusions in patients undergoing ASCT. Additional evidence for the efficacy of a therapeutic platelet transfusion strategy in this patient group was reported by Wandt et $a l^{7}$ They instituted a therapeutic platelet transfusion strategy in consecutive, clinically stable patients undergoing ASCT. Bleeding events were observed in only 26 of the $140(19 \%)$ transplants. The maximum severity was WHO grade 2 , with no grade 3 or 4 bleeding. Notably, $47 \%$ of high-dose melphalan transplants for multiple myeloma (the most common indication for ASCT) were performed without any platelet transfusions and platelet use was decreased by $53 \%$.

Despite the results of these studies, the Canadian ASCT community remains reluctant to embrace and adopt the use of therapeutic platelet strategy in the ASCT setting. At the same, there is an increasing concern that prophylactic platelet transfusions may not be warranted in all patients.

\section{Tranexamic acid: an alternative prophylactic strategy}

Tranexamic acid, an antifibrinolytic agent, is a synthetic analogue of the amino acid lysine and competitively inhibits the activation of plasminogen to plasmin, thereby reducing the degradation of fibrin, a protein that forms the framework of blood clots. It has been extensively studied in surgical settings where it has been shown to consistently reduce bleeding and transfusion needs. ${ }^{32-37}$ Further, it is commonly and safely employed (box 1) in the management of patients with bleeding disorders such as haemophilia and von Willebrand disease. $^{38} 39$

As some patient groups (eg, those undergoing induction therapy for acute leukaemia) appear to be at higher risk for clinically relevant bleeding; efforts are shifting to try and identify strategies to reduce the risk of bleeding while minimising patient exposure to blood products. Consequently, there has been interest in its prophylactic use in patients with haematological malignancies in the context of hypoproliferative thrombocytopenia to prevent bleeding. ${ }^{415}$

Taken together, a strategy using prophylactic tranexamic acid with therapeutic platelet transfusions can be considered a potential substitute for a strategy of prophylactic platelet transfusions in patients at risk for bleeding.

\section{Box 1 Tranexamic acid risks*}

Adverse reactions significant

$>10 \%$ :

1. Central nervous system: headache $(50 \%)$;

2. Gastrointestinal: abdominal pain $(20 \%)$;

3. Neuromuscular and skeletal: back pain $(21 \%)$, muscle pain $(11 \%)$;

4. Respiratory: Nasal/sinus symptoms (25\%).

1-10\%:

1. Central nervous system: fatigue $(5 \%)$;

2. Haematological: anaemia $(6 \%)$;

3. Neuromuscular and skeletal: arthralgia $(7 \%)$, muscle cramps/ spasms $(7 \%)$.

All formulations: $<1 \%$ (limited to important or life threatening): allergic skin reaction, anaphylactic shock, anaphylactoid reactions, cerebral thrombosis, deep vein thrombosis, diarrhoea, dizziness, nausea, pulmonary embolism, renal cortical necrosis, retinal artery/vein obstruction, seizure, ureteral obstruction, visual disturbances (including impaired colour vision and loss), vomiting.

*http://www.uptodate.com/contents/tranexamic-acid-drug-

information?source=preview \&search=\%2Fcontents $\%$

2Fsearch\&anchor=F229896\&selectedTitle=1 78\#F229896.

\section{Assessment of bleeding and QoL associated with} thrombocytopenia in patients undergoing ASCT

Bleeding has been the primary outcome of all the large randomised controlled trials assessing platelet transfusions in patients with haematological malignancies. $^{1}{ }^{3}$ Almost all these trials have used bleeding scores based on the WHO bleeding score, which classifies bleeding into four grades: 1-mild; 2-moderate bleeding not requiring red cell transfusions; 3-moderate to severe bleeding requiring red blood cell transfusion; 4-life-threatening or limb-threatening bleeding. ${ }^{38}$ However, the WHO bleeding score has definite limitations including the lack of precise definitions for each bleeding grade and the lack of formal validation. ${ }^{39} 40$ Grade 2 bleeding or greater bleeding has been used as the primary outcome in most clinical trials, primarily due to rarity of grade 3 and 4 bleeding. The lack of standardisation of bleeding when using the WHO bleeding score has resulted in variation in the type and amount of bleeding reported in clinical trials. ${ }^{41}$ Additionally, the validity of grade 2 bleeding as the primary outcome measure is problematic as grade 2 bleeding does not predict more severe grade 3 or 4 bleeding, and has never been shown to predict mortality or major morbidity, or be associated with changes in quality of life outcomes. ${ }^{39}{ }^{42}$ To address some of these shortcomings in the assessment of bleeding, Webert $e t a t^{43}$ used the measurement theory to develop a validated and reliable bleeding score in patients with haematological malignancies. Outcomes beyond bleeding also need to be considered in clinical trials evaluating platelet transfusions or alternative strategies to prevent bleeding in patients with haematological malignancies. 
Although the rarity of mortality directly related to bleeding precludes its use as a primary outcome in platelet transfusion studies, quality of life is an important outcome that assesses the impact of morbidity related both to bleeding and adverse outcomes related to transfusions or medications. ${ }^{44}{ }^{45}$ Ideally, this would be performed using both general quality of life scales such as the EQ-5D $\mathrm{D}^{46}$ and disease-specific scales for thrombocytopenia such as the FACT-Thrombocytopenia $18 .{ }^{47}$

\section{Patient and caregiver engagement in clinical trial design}

Patient and/or informal caregiver's perspective(s) are rarely considered in clinical trials where healthcare professionals independently determine clinical end points. For instance, what degree of bleeding is important from patient's perspective? Are there psychosocial or anxiety concerns that relate to thrombocytopenia? Which end point(s) are most pertinent from the patient's perspective? As championed by the Patient-Centered Outcomes Research Institute (PCORI), ${ }^{48}$ there has been increasing interest and efforts to engage patients and caregivers to design clinical trials that are relevant and meaningful to the patient. To the best of our knowledge, this has never been studied within the context of bleeding prevention strategies in patients receiving ASCT.

\section{Summary: the importance of the problem}

It is routine clinical practice to administer prophylactic platelets to prevent bleeding in patients undergoing ASCT. However, the true benefit of prophylactic transfusion to prevent bleeding is unknown. Subgroup analyses from three recent studies suggest that this population is at low risk for clinically relevant bleeding $^{6-8}$ and that the number of platelet transfusions can be significantly reduced by adopting a therapeutic transfusion strategy. This approach has not been accepted in practice due to ongoing concerns of bleeding risk.

Platelet transfusions are not benign. Inherent risks include fever, rigors, haemolysis, acute lung injury, transfusion-associated circulatory overload, bacterial and rarely, viral, transmission. ${ }^{9-12}$ The routine use of frequent platelet transfusions may also increase the risk for alloimmune refractoriness, which may increase the difficulty in treating or preventing bleeding complications. The immunomodulatory effect of platelets may increase post-transplant toxicity and increase the risk of tumour progression. ${ }^{5}{ }^{24}$ Platelets, in particular singledonor platelets are often in short supply due to reliance on voluntary donation which has a shelf-life of only 5 days. ${ }^{44}$ Finally, the impact of prophylactic platelet transfusions on the patient's QoL is largely unknown.

In patients undergoing ASCT, an alternative approach to prophylactic platelet transfusions to prevent bleeding is to administer prophylactic tranexamic acid. Tranexamic acid is safe, extensively used to prevent bleeding and reduces red cell transfusions in many clinical settings. In contrast to a solely therapeutic platelet transfusion strategy, this cautious approach has the potential to minimise platelet use and provide this vulnerable population with a safe and effective prophylactic strategy.

In summary, there is a need to reduce the use of unnecessary platelet transfusions and tranexamic acid represents a transfusion-free alternative to prevent bleeding in recipients of ASCT.

\section{Objectives and hypothesis}

We hypothesise that in patients undergoing ASCT, a strategy of prophylactic tranexamic acid with therapeutic platelet transfusions for bleeding (1) is safe, (2) improves QoL and (3) improves economic outcomes as compared to prophylactic platelet transfusions.

\section{Trial overview and design}

PATH is an open-labelled multicentre pilot feasibility parallel-arm 1:1 randomised controlled trial, where participants will be stratified by centre and disease (either myeloma or other haematological malignancy). We will recruit patients over a 2-year period and follow each participant for a minimum of 30 days.

PATH has been funded by a peer-reviewed grant by the Canadian Institutes of Health Transitional Open Grant 2014-2015 (RN260949-342593) and is registered on the National Institute of Health, Clinicaltrials.gov registry (NCT02650791).

\section{METHODS AND ANALYSIS}

Methods and analysis: participants, interventions and outcomes

Study setting

PATH will be carried out at 3-4 tertiary adult haematopoietic stem cell transplant centres in Canada.

\section{Eligibility criteria}

Recipients of ASCT will be screened for study eligibility prior to the initiation of conditioning chemotherapy and/or radiotherapy. Screening will occur, ideally in a dedicated outpatient clinic prior to hospital admission for ASCT. Inclusion and exclusion criteria will have to be satisfied prior to randomisation as outlined in the Inclusion criteria and Exclusion criteria sections. Randomisation will be performed on day 0 of the ASCT. Verification that patients still meet all inclusion and exclusion criteria will occur prior to patients being randomised.

\section{Inclusion criteria}

1. Adults 18 years or older undergoing ASCT for a haematological malignancy;

2. Patients providing written informed consent prior to starting transplantation. 


\section{Exclusion criteria}

1. A previous WHO grade 3 or 4 bleeding event;

2. A WHO grade 2 bleeding event within the past year;

3. A previous or current thrombotic event defined as a pulmonary embolism, deep vein thrombosis, cerebral thrombosis;

4. Active angina (chest pain of presumed cardiac origin either at rest or with activity);

5. Current or previous (within 2 weeks) urinary tract bleeding;

6. An inherited haemostatic or thrombotic disorder;

7. Coagulopathy defined as a prothrombin time or activated partial thromboplastin time more than 1.5 times the upper limit of normal or fibrinogen $<2 \mathrm{~g} / \mathrm{L}$;

8. A requirement for anticoagulant or antiplatelet drugs;

9. Previously documented history of refractoriness to platelet transfusion secondary to HLA antibodies;

10. Significant renal impairment (creatinine more than 1.5 times the upper limit of normal);

11. Pregnant or breast feeding;

12. Unwilling or unable to provide informed consent;

13. Participant has known history of subarachnoid haemorrhage;

14. Participant has acquired disturbances to his/her colour vision;

15. Participant has known sensitivity or allergy to tranexamic acid or any of its ingredients;

16. Current use of oral contraceptive pill (birth control pill), hormonal contraceptives or hormone replacement therapy.

The use of any other concomitant medications would be at the discretion of the treating physician and his/her team.

\section{Interventions}

All patients undergoing ASCT have daily morning laboratory investigations, including a complete blood count (CBC), performed as part of standard care. We will randomise patients to one of the following bleeding prevention strategies from the day of stem cell infusion (day 0) until platelet engraftment (defined as the first of two consecutive measured platelet counts on different days that are $>20 \times 10^{9} / \mathrm{L}$ and increasing in the absence of a platelet transfusion for three consecutive days, or day 30 post-ASCT, whichever comes first):

\section{Control arm: prophylactic platelet transfusion strategy}

Patients allocated to the prophylactic platelet transfusion group will receive a platelet transfusion when the measured platelet count is $<10 \times 10^{9} / \mathrm{L}$.

\section{Experimental arm: prophylactic tranexamic acid strategy}

Patients allocated to the prophylactic tranexamic acid group will receive a standardised routine oral dose of tranexamic acid, $1 \mathrm{~g}$ three times daily. Tranexamic acid will start when the platelet count is $<50 \times 10^{9} / L$ and continue until platelet engraftment. Patients in this group will not receive routine prophylactic platelet transfusions.

This is not a blinded study. All patients will have their platelet count checked daily or as per institutional policy until platelet engraftment. All patients in both study arms will receive therapeutic platelet transfusions to treat clinically relevant bleeding, defined as WHO bleeding of grade 2 or greater. The $\mathrm{WHO}$ grading system is the most commonly used tool in the assessment of bleeding events in platelet transfusion trials. ${ }^{41}$ In this system, bleeding episodes are categorised as grade 1 (mild), grade 2 (moderate; red cell transfusion no needed immediately), grade 3 (severe; requiring red cell transfusion within 24 hours) and grade 4 (debilitating or life threatening; see table 2) ${ }^{38}$ Further, we will also assess bleeding using the Bleeding Severity Measurement Scale (BSMS). ${ }^{43}$

\section{Therapeutic platelet transfusions}

All patients may receive therapeutic platelet transfusions for grade 2 bleeding or greater regardless of the platelet count. Therapeutic platelet transfusions can also be given to patients who become clinically unstable, defined as the presence of fever, active infection or hypotension, and those who require an invasive procedure. Therapeutic platelet transfusions may be administered at any time at the clinician's discretion and the rationale will be recorded. The type of platelet product will follow local institutional practices.

\section{Source of progenitor cells, conditioning regimen and supportive care}

For all patients, the choice of progenitor cells and conditioning regimen will be determined by the centre and by availability. Similarly, the supportive care strategy will be determined by local institutional policy. This will include, but not limited to the use of antibiotics, analgesia, intravenous fluids, growth factors and other blood products (not including platelets).

\begin{tabular}{|c|c|}
\hline Score & Bleeding symptoms \\
\hline 0 & None \\
\hline 1 & $\begin{array}{l}\text { Petechiae, ecchymosis, occult blood in body } \\
\text { secretions, mild vaginal spotting, epistaxis lasting } \\
<30 \text { min }\end{array}$ \\
\hline 2 & $\begin{array}{l}\text { Evidence of gross haemorrhage not requiring red } \\
\text { cell transfusion over routine transfusion needs: } \\
\text { epistaxis lasting } \geq 30 \text { min, haematuria, } \\
\text { haematemesis, haematoma, haematochezia }\end{array}$ \\
\hline 3 & $\begin{array}{l}\text { Haemorrhage requiring transfusion of one or more } \\
\text { units of red cells within } 24 \text { hours }\end{array}$ \\
\hline 4 & $\begin{array}{l}\text { Life-threatening haemorrhage, defined as either } \\
\text { massive bleeding causing haemodynamic } \\
\text { compromise or bleeding into a vital organ } \\
\text { (eg, intracranial, pericardial or pulmonary } \\
\text { haemorrhage) or death }\end{array}$ \\
\hline
\end{tabular}




\section{Outcomes}

\section{Primary outcome (feasibility)}

The primary outcomes of this feasibility trial will be:

1. Enrolment,

2. Number of off-protocol platelet transfusions and

3. Total number of platelet transfusion per group.

4. Adherence to tranexamic acid use.

We will evaluate feasibility by:

1. Recruitment of an average of two patients per month per site,

2. Fewer than $10 \%$ off-protocol transfusions in each arm and

3. An absolute reduction of $25 \%$ in the total number of platelet transfusions in the tranexamic acid arm.

4. Adherence to tranexamic acid use. Adherence to tranexamic acid use will be defined as follows: excellent $(\geq 90 \%$ consumed), acceptable (between $75 \%$ and $90 \%$ consumed), poor ( $\leq 75 \%$ consumed). We anticipate acceptable to excellent adherence given that study participants will be cared for in an inpatient setting.

During the feasibility trial we will identify any logistical issues related to protocol implementation, randomisation strategy or data collection. Furthermore, we will define the sample size required for the definitive trial.

\section{Secondary outcomes (clinical)}

The secondary outcomes of this trial will be:

1. WHO bleeding events of grade 2 or higher; ${ }^{38}$

2. WHO bleeding events of grade 3 or $4 ;^{38}$

3. Time from randomisation to bleeding of $\mathrm{WHO}$ grade 2 or higher; ${ }^{38}$

4. Number of days with bleeding of WHO grade 2 or higher;
5. $\quad$ BSMS (table 3$)^{43}$ bleeding events of grade 2 :

- Previous studies have used the WHO bleeding scale and have reported substantial interobserver variability in scoring. ${ }^{41}$ Hence, we have elected to use a validated score that has been shown to minimise this variability, in addition to the WHO scale in order to facilitate comparison with other large clinical trials;

6. Number of platelet transfusions;

7. Number of red cell transfusions;

8. Time to platelet count recovery;

9. Number of days with platelet count $<10 \times 10^{9} / \mathrm{L}$;

10. Length of hospital stay;

11. Number and type of adverse transfusion reactions;

12. Bearman toxicity score (table 4$) ;^{49}$

13. Incidence of infections at day 30 following ASCT:

- Clinically important infections will be ascertained using Centre for Disease Control criteria where grade 4 and 5 infections will be recorded;

14. Mortality at day 30 ;

15. Quality of life measures: FACT-Thrombocytopenia 18 (table 5), ${ }^{47}$ FACT-bone marrow transplantation (BMT) (table 6), ${ }^{50}$ generalised anxiety disorder (GAD)-7 (table 7$)^{51}$ and EQ-5D (table 8$) ;{ }^{46}$

16. Economic analyses: incremental cost-effectiveness ratios.

\section{Participant timeline}

All patients will be followed for 30 days post-ASCT. The assigned treatment protocol will be applied from day 0 of ASCT till the day of platelet engraftment or day 30, whichever comes first. Assessments of clinical outcomes will occur as detailed in table 9 until day 30 .

Table 3 Bleeding Severity Measurement Scale (BSMS)

\section{Bleeding grade and} classification

0 . No bleeding

1. Not clinically significant 1(a) Trace bleeding bleeding

1(b) Mild bleeding

2. Clinically significant bleeding

\section{Description of bleeding}

No bleeding

Minimal bleeding or bleeding detectable by laboratory measures only. Bleeding does not have any impact on patient or on the level of care provided to the patient.

Non-clinically significant bleeding. Bleeding does not have any impact on patient or level of care provided to the patient.

2(a) Serious bleeding

Bleeding directly resulting in one or more of the following:

- Significant pain (requiring medical treatment or intervention)

- Need for interventions (including transfusion, surgery, invasive procedures, administration of medication, etc)

2(b) Serious bleeding Any bleeding meeting one or more of the following criteria: causing significant morbidity

- All central nervous system bleeding

- Resulting in haemodynamic instability:

- Tachycardia (increase in resting heart rate by at least $20 \mathrm{bpm}$ ) or

- Hypotension (decrease in systolic and/or diastolic BP by at least $20 \mathrm{~mm} \mathrm{Hg}$ )

- Resulting in vision loss

- Resulting in significant morbidity

2(c) Fatal bleeding
Any bleeding directly contributing to patient's death 
Table 4 Bearman toxicity grading scale

\begin{tabular}{ll}
\hline Toxicity & Grade 1 \\
\hline Heart & Mild ECG abnormality, not \\
& $\begin{array}{l}\text { requiring medical intervention; or } \\
\text { noted heart enlargement on CXR } \\
\text { with no clinical symptoms }\end{array}$
\end{tabular}

Bladder Macroscopic haematuria after 2 days from last chemotherapy dose with no subjective symptoms of cystitis and not caused by infection

Kidney Increase in creatinine up to twice the baseline value

Lung Dyspnoea without CXR changes not caused by infection or congestive heart failure; or CXR showing isolated infiltrate or mild interstitial changes without symptoms not caused by infection or congestive heart failure

Liver Mild hepatic dysfunction with $2.0 \mathrm{mg} / \mathrm{dL}<$ bilirubin $<6.0 \mathrm{mg} / \mathrm{dL}$ or weight gain $>2.5 \%$ and $<5 \%$ from baseline, of non-cardiac origin; or serum AST increase more than twofold but less than fivefold from lowest preconditioning

CNS Somnolence but the patient is easily arousable and oriented after arousal

Stomatitis Pain and/or ulceration not requiring a continuous intravenous narcotic drug

\section{Grade 2}

Grade 3

Moderate ECG abnormalities requiring and responding to medical intervention; or requiring continuous monitoring without treatment; or congestive heart failure responsive to digitalis or diuretics

Macroscopic haematuria after 7 days from last chemotherapy dose not caused by infection; or haematuria after 2 days with subjective symptoms of cystitis not caused by infection Increase in creatinine above twice baseline but not requiring dialysis CXR with extensive localised infiltrate or moderate interstitial changes combined with dyspnoea and not caused by infection or $\mathrm{CHF}$; or decrease of $\mathrm{PO}_{2}(>10 \%$ from baseline) but not requiring mechanical ventilation or $>50 \% \mathrm{O}_{2}$ on mask and not caused by infection Moderate hepatic dysfunction with bilirubin $>6 \mathrm{mg} / \mathrm{dL}<20 \mathrm{mg} / \mathrm{dL}$; or serum AST increase more than fivefold from preconditioning; or clinical ascites or image-documented ascites $>100 \mathrm{~mL}$; or weight gain $>5 \%$ from baseline of non-cardiac origin Somnolence with confusion after arousal; or other new objective CNS symptoms with no loss of consciousness not more easily explained by other medication, bleeding, or CNS infection Pain and/or ulceration requiring a continuous intravenous narcotic drug (morphine drip)

Watery stools $>2000 \mathrm{~mL}$ every day not related to infection; or macroscopic haemorrhagic stools with no effect on cardiovascular status not caused by infection; or subileus not related to infection
Severe ECG abnormalities with no or only partial response to medical intervention; or heart failure with no or only minor response to medical intervention: or decrease in voltage by more than $50 \%$

Haemorrhagic cystitis with frank blood, necessitating invasive local intervention with installation of sclerosing agents, nephrostomy or other surgical procedures Requirement of dialysis

Interstitial changes requiring mechanical ventilator support or $>50 \%$ oxygen on mask and not caused by infection or CHF

Severe hepatic dysfunction with bilirubin >20 mg/dL; or hepatic encephalopathy; or ascites compromising respiratory function

Seizures or coma not explained (documented) by other medication, CNS infection, or bleeding

Severe ulceration and/or mucositis requiring preventive intubation; or resulting in documented aspiration pneumonia with or without intubation

lleus requiring nasogastric suction and/or surgery and not related to infection; or haemorrhagic enterocolitis affecting cardiovascular status and requiring transfusion

AST, aspartate transaminase; CHF, congestive heart failure; CNS, central nervous system; CXR, chest X-ray; GI, gastrointestinal.

A detailed review of the patient record, laboratory and diagnostic tests will be included during the hospitalisation. Research staff will follow all patients daily for the duration of the study period. Participants will be asked to report any possible adverse events immediately. Adherence to protocol will be appraised by: (1) nursing documentation in an inpatient setting, and (2) selfreported medication adherence form in an outpatient setting.

Patients will have their blood counts measured daily or as per institutional policy while on study. More frequent monitoring may be performed at the discretion of the treating physician.

\section{Sample size}

As a pilot trial, the primary consideration for the sample size is the ability to inform the feasibility of a full-scale study. We propose a sample size of 50 adults in each treatment group for a total sample size of 100, while stratifying for participants with either myeloma or any other haematological malignancy. 


\begin{tabular}{|c|c|c|c|c|c|c|}
\hline & & $\begin{array}{l}\text { Not } \\
\text { at all }\end{array}$ & $\begin{array}{l}\text { A little } \\
\text { bit }\end{array}$ & $\begin{array}{l}\text { Some } \\
\text { what }\end{array}$ & $\begin{array}{l}\text { Quite } \\
\text { a bit }\end{array}$ & $\begin{array}{l}\text { Very } \\
\text { much }\end{array}$ \\
\hline \multicolumn{7}{|c|}{ Physical well-being } \\
\hline GP1 & I have a lack of energy & 0 & 1 & 2 & 3 & 4 \\
\hline GP2 & I have nausea & 0 & 1 & 2 & 3 & 4 \\
\hline GP3 & $\begin{array}{l}\text { Because of my physical condition, I have trouble meeting the needs of my } \\
\text { family }\end{array}$ & 0 & 1 & 2 & 3 & 4 \\
\hline GP4 & I have pain & 0 & 1 & 2 & 3 & 4 \\
\hline GP5 & I am bothered by side effects of treatment & 0 & 1 & 2 & 3 & 4 \\
\hline GP6 & I feel ill & 0 & 1 & 2 & 3 & 4 \\
\hline GP7 & I am forced to spend time in bed & 0 & 1 & 2 & 3 & 4 \\
\hline \multicolumn{7}{|c|}{ Social/family well-being } \\
\hline GS1 & I feel close to my friends & 0 & 1 & 2 & 3 & 4 \\
\hline GS2 & I get emotional support from my family & 0 & 1 & 2 & 3 & 4 \\
\hline GS3 & I get support from my friends & 0 & 1 & 2 & 3 & 4 \\
\hline GS4 & My family has accepted my illness & 0 & 1 & 2 & 3 & 4 \\
\hline GS5 & I am satisfied with family communication about my illness & 0 & 1 & 2 & 3 & 4 \\
\hline GS6 & I feel close to my partner (or the person who is my main support) & 0 & 1 & 2 & 3 & 4 \\
\hline Q1 & $\begin{array}{l}\text { Regardless of your current level of sexual activity, please answer the followir } \\
\text { please mark this box } \square \text { and go to the next section. }\end{array}$ & g quest & ion. If you & & & swer it, \\
\hline GS7 & I am satisfied with my sex life & 0 & 1 & 2 & 3 & 4 \\
\hline \multicolumn{7}{|c|}{ Emotional well-being } \\
\hline GE1 & I feel sad & 0 & 1 & 2 & 3 & 4 \\
\hline GE2 & I am satisfied with how I am coping with my illness & 0 & 1 & 2 & 3 & 4 \\
\hline GE3 & I am losing hope in the fight against my illness & 0 & 1 & 2 & 3 & 4 \\
\hline GE4 & I feel nervous & 0 & 1 & 2 & 3 & 4 \\
\hline GE5 & I worry about dying & 0 & 1 & 2 & 3 & 4 \\
\hline GE6 & I worry that my condition will get worse & 0 & 1 & 2 & 3 & 4 \\
\hline \multicolumn{7}{|c|}{ Functional well-being } \\
\hline GF1 & I am able to work (include work at home) & 0 & 1 & 2 & 3 & 4 \\
\hline GF2 & My work (include work at home) is fulfilling & 0 & 1 & 2 & 3 & 4 \\
\hline GF3 & I am able to enjoy life & 0 & 1 & 2 & 3 & 4 \\
\hline GF4 & I have accepted my illness & 0 & 1 & 2 & 3 & 4 \\
\hline GF5 & I am sleeping well & 0 & 1 & 2 & 3 & 4 \\
\hline GF6 & I am enjoying the things I usually do for fun & 0 & 1 & 2 & 3 & 4 \\
\hline GF7 & I am content with the quality of my life right now & 0 & 1 & 2 & 3 & 4 \\
\hline \multicolumn{7}{|c|}{ Additional concerns } \\
\hline An5 & I have energy 0 & 0 & 1 & 2 & 3 & 4 \\
\hline An7 & I am able to do my usual activities 0 & 0 & 1 & 2 & 3 & 4 \\
\hline Th1 & I bleed easily 0 & 0 & 1 & 2 & 3 & 4 \\
\hline Th2 & I bruise easily 0 & 0 & 1 & 2 & 3 & 4 \\
\hline Th3 & I worry about problems with bruising or bleeding 0 & 0 & 1 & 2 & 3 & 4 \\
\hline Th4 & I worry about the possibility of serious bleeding 0 & 0 & 1 & 2 & 3 & 4 \\
\hline Th5 & I am bothered by nosebleeds 0 & 0 & 1 & 2 & 3 & 4 \\
\hline Th6 & I am bothered by bleeding in my gums or mouth 0 & 0 & 1 & 2 & 3 & 4 \\
\hline Th7 & I am bothered by pinpoint bruising beneath my skin 0 & 0 & 1 & 2 & 3 & 4 \\
\hline Th8 & I am bothered by blood in my urine or stool 0 & 0 & 1 & 2 & 3 & 4 \\
\hline Th9 & I am inconvenienced by platelet transfusions 0 & 0 & 1 & 2 & 3 & 4 \\
\hline $\mathrm{HI}$ & I feel fatigued 0 & 0 & 1 & 2 & 3 & 4 \\
\hline Th 10 & $\begin{array}{l}\text { I avoid or limit physical activity (because of concern with bleeding or } \\
\text { bruising) } 0\end{array}$ & 0 & 1 & 2 & 3 & 4 \\
\hline Th11 & I avoid or limit social activity (because of concern with bleeding or bruising) 0 & 0 & 1 & 2 & 3 & 4 \\
\hline Th 12 & I am frustrated by not being able to do my usual activities 0 & 0 & 1 & 2 & 3 & 4 \\
\hline Th 13 & I worry that my treatment will be delayed (because of low blood counts) 0 & 0 & 1 & 2 & 3 & 4 \\
\hline Th14 & $\begin{array}{l}\text { I worry that my treatment dose will be reduced (because of low blood } \\
\text { counts) } 0\end{array}$ & 0 & 1 & 2 & 3 & 4 \\
\hline Th 15 & For women only: I am bothered by vaginal bleeding 0 & 0 & 1 & 2 & 3 & 4 \\
\hline
\end{tabular}

Below is a list of statements that other people with your illness have said are important. Please circle or mark one number per line to indicate your response as it applies to the past 7 days. 


\begin{tabular}{|c|c|c|c|c|c|c|}
\hline & & Not at all & $\begin{array}{l}\text { A little } \\
\text { bit }\end{array}$ & Some-what & $\begin{array}{l}\text { Quite } \\
\text { a bit }\end{array}$ & $\begin{array}{l}\text { Very } \\
\text { much }\end{array}$ \\
\hline \multicolumn{7}{|c|}{ Physical well-being } \\
\hline GP1 & I have a lack of energy. & 0 & 1 & 2 & 3 & 4 \\
\hline GP2 & I have nausea. & 0 & 1 & 2 & 3 & 4 \\
\hline GP3 & $\begin{array}{l}\text { Because of my physical condition, I have trouble meeting the needs } \\
\text { of my family. }\end{array}$ & 0 & 1 & 2 & 3 & 4 \\
\hline GP4 & I have pain. & 0 & 1 & 2 & 3 & 4 \\
\hline GP5 & I am bothered by side effects of treatment. & 0 & 1 & 2 & 3 & 4 \\
\hline GP6 & I feel ill. & 0 & 1 & 2 & 3 & 4 \\
\hline GP7 & I am forced to spend time in bed. & 0 & 1 & 2 & 3 & 4 \\
\hline \multicolumn{7}{|c|}{ Social/family well-being } \\
\hline GS1 & I feel close to my friends. & 0 & 1 & 2 & 3 & 4 \\
\hline GS2 & I get emotional support from my family. & 0 & 1 & 2 & 3 & 4 \\
\hline GS3 & I get support from my friends. & 0 & 1 & 2 & 3 & 4 \\
\hline GS4 & My family has accepted my illness. & 0 & 1 & 2 & 3 & 4 \\
\hline GS5 & I am satisfied with family communication about my illness. & 0 & 1 & 2 & 3 & 4 \\
\hline GS6 & I feel close to my partner (or the person who is my main support). & 0 & 1 & 2 & 3 & 4 \\
\hline Q1 & $\begin{array}{l}\text { Regardless of your current level of sexual activity, please answer } \\
\text { the following question. If you prefer not } \square \text { to answer it, please mark } \\
\text { this box and go to the next section. }\end{array}$ & & & & & \\
\hline GS7 & I am satisfied with my sex life. & 0 & 1 & 2 & 3 & 4 \\
\hline \multicolumn{7}{|c|}{ Emotional well-being } \\
\hline GE1 & I feel sad. & 0 & 1 & 2 & 3 & 4 \\
\hline GE2 & I am satisfied with how I am coping with my illness. & 0 & 1 & 2 & 3 & 4 \\
\hline GE3 & I am losing hope in the fight against my illness. & 0 & 1 & 2 & 3 & 4 \\
\hline GE4 & I feel nervous. & 0 & 1 & 2 & 3 & 4 \\
\hline GE5 & I worry about dying. & 0 & 1 & 2 & 3 & 4 \\
\hline GE6 & I worry that my condition will get worse. & 0 & 1 & 2 & 3 & 4 \\
\hline \multicolumn{7}{|c|}{ Functional well-being } \\
\hline GF1 & I am able to work (include work at home). & 0 & 1 & 2 & 3 & 4 \\
\hline GF2 & My work (include work at home) is fulfilling. & 0 & 1 & 2 & 3 & 4 \\
\hline GF3 & I am able to enjoy life. & 0 & 1 & 2 & 3 & 4 \\
\hline GF4 & I have accepted my illness. & 0 & 1 & 2 & 3 & 4 \\
\hline GF5 & I am sleeping well. & 0 & 1 & 2 & 3 & 4 \\
\hline GF6 & I am enjoying the things I usually do for fun. & 0 & 1 & 2 & 3 & 4 \\
\hline GF7 & I am content with the quality of my life right now. & 0 & 1 & 2 & 3 & 4 \\
\hline \multicolumn{7}{|c|}{ Additional concerns } \\
\hline BMT1 & I am concerned about keeping my job (include work at home). & 0 & 1 & 2 & 3 & 4 \\
\hline BMT2 & I feel distant from other people. & 0 & 1 & 2 & 3 & 4 \\
\hline ВMT3 & I worry that the transplant will not work. & 0 & 1 & 2 & 3 & 4 \\
\hline BMT4 & The side effects of treatment are worse than I had imagined. & 0 & 1 & 2 & 3 & 4 \\
\hline C6 & I have a good appetite. & 0 & 1 & 2 & 3 & 4 \\
\hline C7 & I like the appearance of my body. & 0 & 1 & 2 & 3 & 4 \\
\hline BMT5 & I am able to get around by myself. & 0 & 1 & 2 & 3 & 4 \\
\hline BMT6 & I get tired easily. & 0 & 1 & 2 & 3 & 4 \\
\hline BL4 & I am interested in sex. & 0 & 1 & 2 & 3 & 4 \\
\hline BMT7 & I have concerns about my ability to have children. & 0 & 1 & 2 & 3 & 4 \\
\hline ВMT8 & I have confidence in my nurse(s). & 0 & 1 & 2 & 3 & 4 \\
\hline ВMT9 & I regret having the bone marrow transplant & 0 & 1 & 2 & 3 & 4 \\
\hline BMT10 & I can remember things. & 0 & 1 & 2 & 3 & 4 \\
\hline $\mathrm{Br} 1$ & I am able to concentrate. & 0 & 1 & 2 & 3 & 4 \\
\hline BMT11 & I have frequent colds/infections. & 0 & 1 & 2 & 3 & 4 \\
\hline BMT12 & My eyesight is blurry. & 0 & 1 & 2 & 3 & 4 \\
\hline BMT13 & I am bothered by a change in the way food tastes & 0 & 1 & 2 & 3 & 4 \\
\hline BMT14 & I have tremors. & 0 & 1 & 2 & 3 & 4 \\
\hline B1 & I have been short of breath. & 0 & 1 & 2 & 3 & 4 \\
\hline BMT15 & I am bothered by skin problems (eg, rash, itching) & 0 & 1 & 2 & 3 & 4 \\
\hline
\end{tabular}


Table 6 Continued

\begin{tabular}{|c|c|c|c|c|c|}
\hline & Not at all & $\begin{array}{l}\text { A little } \\
\text { bit }\end{array}$ & Some-what & $\begin{array}{l}\text { Quite } \\
\text { a bit }\end{array}$ & $\begin{array}{l}\text { Very } \\
\text { much }\end{array}$ \\
\hline BMT16 I have trouble with my bowels. & 0 & 1 & 2 & 3 & 4 \\
\hline BMT17 My illness is a personal hardship for my close family members. & 0 & 1 & 2 & 3 & 4 \\
\hline BMT18 The cost of my treatment is a burden on me or my family. & 0 & 1 & 2 & 3 & 4 \\
\hline
\end{tabular}

Above is a list of statements that other people with your illness have said are important. Please circle or mark one number per line to indicate your response as it applies to the past 7 days.

\section{Table 7 GAD-7}

\begin{tabular}{lllll}
\hline $\begin{array}{l}\text { Over the past } 2 \text { weeks, how often have you been bothered } \\
\text { by any of the following problems? }\end{array}$ & Not at all & $\begin{array}{l}\text { Several } \\
\text { days }\end{array}$ & $\begin{array}{l}\text { More than } \\
\text { half the days }\end{array}$ & $\begin{array}{l}\text { Nearly every } \\
\text { day }\end{array}$ \\
\hline Feeling nervous, anxious or on edge & 0 & 1 & 2 & 3 \\
Not being able to stop or control worrying & 0 & 1 & 2 & 3 \\
Worrying too much about different things & 0 & 1 & 2 & 3 \\
Trouble relaxing & 0 & 1 & 2 & 3 \\
Being so restless that it is hard to sit still & 0 & 1 & 2 & 3 \\
Becoming easily annoyed or irritable & 0 & 1 & 2 & 3 \\
Feeling afraid as if something awful might happen & 0 & 1 & 2 & 3 \\
\hline
\end{tabular}

\section{Recruitment}

Each site performs $\sim 60$ ASCTs per year. Importantly, there is already an infrastructure and system in place for participating sites given that they are participating in an ongoing red cell transfusion trigger study in patients receiving HSCT. Conservatively, we aim to recruit two patients per month at each participating site.

\section{METHODS AND ANALYSIS: ASSIGNMENT OF INTERVENTIONS}

Allocation (sequence generation, allocation concealment mechanism) and implementation

Patients will be stratified by centre and disease (multiple myeloma vs other haematological malignancies) given that the underlying disease may affect the bleeding risk and the most common indication for ASCT is multiple myeloma.

Further, they will then be assigned either of the transfusion strategies by block randomisation to optimise balance between the two treatment arms. The randomisation sequence will be determined by the Ottawa Methods Centre (Ottawa Hospital Research Institute) by computer-generated random numbers where random blocks of two and four for each participating centre will help facilitate balance.

The Ottawa Methods Centre at the Ottawa Hospital Research Institute will design and maintain web-based randomisation forms. The forms will contain a checklist of eligibility criteria as described in Inclusion criteria and Exclusion criteria sections. The local investigator and/or designate will 'check-off' and acknowledge patient eligibility. If all the criteria are met, then randomisation will be completed, and the site will be informed of the study arm assigned by email. The recipient will be considered enrolled in the trial at the time of consent.

Selection bias will be minimised by random allocation to treatment groups and by concealing allocation.

Randomisation of study participants is a valid and justified method to protect against selection biases. Similarly, co-intervention and confounding would be minimised by the randomised design. The web-based computerised randomisation system as described above will be used to ensure that the participating centre and individuals remain unaware of the randomisation sequence. Concealment of randomisation prevents selection bias by ensuring that the participating centres and individuals remain unaware of the randomisation sequence. Medical and research staff, and investigators, will be blinded to randomisation scheme.

\section{Blinding}

An open-labelled design is more prone to ascertainment bias than a double-blind trial. However, this should not affect the feasibility outcomes. Moreover, it would be impractical to blind participants and healthcare professionals to the assigned bleeding prevention strategy. First, a placebo transfusion is not feasible as blinding the treating physicians would compromise safety in making clinical decisions about platelet transfusions in circumstances associated with an increased risk of bleeding. As such, a placebo medication would be impractical given that it would then be clear which arm is receiving the prophylactic platelet transfusion strategy.

Importantly, recent clinical trials of platelet dose that have attempted to blind participants and physicians have 
Table 8 EQ-5D

\section{By placing a tick in one box in each group below, please indicate which statements best describe your own health state today.}

\section{Mobility}

I have no problems in walking about.

I have some problems in walking about.

$\square$

I am confined to bed.

Self-care

I have no problems with self-care.

I have some problems washing or dressing myself.

I am unable to wash or dress myself.

Usual activities (eg, work, study, housework, family or leisure activities)

I have no problems with performing my usual activities.

I have some problems with performing my usual activities.

I am unable to perform my usual activities.

Pain/discomfort

I have no pain or discomfort.

I have moderate pain or discomfort.

I have extreme pain or discomfort.

Anxiety/depression

I am not anxious or depressed.

I am moderately anxious or depressed.

I am extremely anxious or depressed.

We would like the patient to indicate on this scale how good or bad the patient's own health is on a particular day, in patient's opinion. They should do this by drawing a line from the box below to whichever point on the scale indicates how good or bad the patient's state of health is on a particular day. not been successful as the patients and clinicians were aware of allocation based on the platelet counts and the size of the platelet product. ${ }^{1}$ Further, the standard of care requires daily knowledge of platelet count to ensure participants' overall care and safety. We will further reduce ascertainment bias by objectively grading bleeding events using the WHO and BSMS bleeding score.

\section{METHODS AND ANALYSIS: DATA COLLECTION, MANAGEMENT AND ANALYSIS \\ Data collection methods}

Information will be collected and recorded on case report forms (CRF). These will be completed at study entry (registration and randomisation), day 0 (first day of stem cell infusion) and on an ongoing basis until day 30 post-ASCT (or until time of death, whichever is earlier). Copies of the completed CRFs are to be submitted to the Project Management Office within 30 days of day 0 and day 30. The original CRFs and questionnaires will be sent to the coordinating centre. Source documentation and copies of CRFs and questionnaires will be stored at each site.

\section{Data management}

The Ottawa Methods Centre will perform the randomisation, data collection and statistical support while the multicentre coordinator will oversee management, site monitoring, administration and meeting support. A centralised database will be used and stored on a secure server with daily backup. The multicentre coordinator will also communicate with data management and clinical research personnel in each of the participating institutions.

\section{Statistical methods}

Binary/categorical end points will be compared between treatment groups using logistic regression. Both an 'intention-to-treat' and on-protocol analysis will be performed. 'Intention-to-treat' analysis will be supplemented by a sensitivity analysis that excludes patients who were non-compliant or lost to follow-up.

Where appropriate, analyses will employ a two-tailed test for significance to account for the possibility that either treatment arm may be beneficial. Analysis of time-to-failure end points will make use of Kaplan-Meier estimates, log-rank tests and Cox proportional hazards models as appropriate. Binary and categorical end points will be compared between treatment groups using logistic regression. The results for each of the end points will be summarised using significance tests at the level of 0.05 and $95 \%$ CIs. Analysis of secondary end points will be considered exploratory and hypothesis generating.

We will also perform recurrent event analysis for bleeding events as proposed by Cook et al. ${ }^{17}{ }^{52} \mathrm{QOL}$ data will be summarised using a combination of descriptive statistics and side-by-side box plots showing 
Table 9 Schedule of activities

\begin{tabular}{|c|c|c|c|c|c|c|c|}
\hline Type of visit & Screening & Enrolment & Randomisation & Week 1 & Week 2 & Week 3 & Week 4 \\
\hline \multicolumn{8}{|l|}{ Screening } \\
\hline Timing of visit & & Pre-ASCT* & Day 0 & & & & \\
\hline Confirm eligibility criteria & $\mathrm{X}$ & $\mathrm{x}$ & $x$ & & & & \\
\hline Informed consent & $\mathrm{X}$ & & & & & & \\
\hline \multicolumn{8}{|l|}{ Baseline characteristics } \\
\hline Demographic data & & $x$ & & & & & \\
\hline Disease, treatment history & & $x$ & & & & & \\
\hline $\begin{array}{l}\text { ECOG and Karnofsky performance } \\
\text { status }\end{array}$ & & $x$ & & & & & \\
\hline Comorbidities & & $x$ & & & & & \\
\hline Bleeding history & & $x$ & & & & & \\
\hline $\begin{array}{l}\text { Bleeding assessment } \\
\text { (WHO and BSMS) }\end{array}$ & & $x$ & & & & & \\
\hline \multicolumn{8}{|l|}{ Interventionst } \\
\hline $\begin{array}{l}\text { Daily oral tranexamic acid } \ddagger \text { or } \\
\text { prophylactic platelets } \S\end{array}$ & & & & $x$ & $x$ & $\mathrm{X}$ & $x$ \\
\hline \multicolumn{8}{|l|}{ Assessments } \\
\hline Complete blood countף & & & $x$ & $x$ & $x$ & $x$ & $x$ \\
\hline $\begin{array}{l}\text { Daily bleeding assessments } \\
\text { (WHO and BSMS) } \dagger\end{array}$ & & & $x$ & $x$ & $x$ & $x$ & $\mathrm{x}$ \\
\hline Bearman toxicity scale & & & & & & & $x$ \\
\hline $\begin{array}{l}\text { Daily } \mathrm{NCl} \text { Toxicity Criteria Assessme } \\
\text { and AEs }\end{array}$ & for SAEs & & & $x$ & $x$ & $x$ & $x$ \\
\hline \multicolumn{8}{|l|}{ Quality of life assessments** } \\
\hline FACT-BMT & & $x$ & & $x$ & $x$ & $x$ & $x$ \\
\hline FACT-Thrombocytopenia 18 & & $x$ & & $x$ & $x$ & $x$ & $x$ \\
\hline$E Q-5 D$ & & $x$ & & $x$ & $x$ & $x$ & $x$ \\
\hline GAD-7 & & $x$ & & $x$ & $x$ & $x$ & $x$ \\
\hline \multicolumn{8}{|c|}{$\begin{array}{l}\text { *The enrolment visit should occur within } 14 \text { days prior to start of conditioning chemotherapy. } \\
\text { †From day } 0 \text { until platelet engraftment or day } 30 \text {, whichever occurs first. } \\
\text { fFrom first day with platelet count }<50 \times 10^{9} / \mathrm{L} \text { until platelet engraftment or day } 30 \text {, whichever occurs first. } \\
\text { §Prophylactic platelets to be prescribed as per institutional practice. } \\
\text { १Daily or as per institutional policy. } \\
\text { ** Quality of life assessments to be performed once a week } \pm 2 \text { days. } \\
\text { AE, adverse event; ASCT, autologous haematopoietic stem cell transplantations; BSMS, Bleeding Severity Measurement Scale; ECOG, } \\
\text { Eastern Cooperative Oncology Group; SAE, serious adverse event. }\end{array}$} \\
\hline
\end{tabular}

distribution of scores over time. A further analysis across time points will be performed using repeated-measures analysis of variance and any transformation to the raw data when statistically appropriate.

All data will be analysed centrally through the Clinical Epidemiology Program and Centre for Transfusion Research in Ottawa.

\section{METHODS AND ANALYSIS: MONITORING} Data monitoring

The multicentre coordinator will review the protocol and CRFs with the investigator and study staff before study initiation at the site initiation visit or the investigator's meeting. A monitor will visit sites as needed throughout the duration of the study to verify the quality of data and to ensure that the standards of Good Clinical Practice are being met. A monitoring plan will be developed and adhered to throughout the duration of the study.

During the course of the study, an independent Data Safety Monitoring Board (DSMB) will be set up to review efficacy and safety data. The DSMB will consist of a Chair and two members. The members will have expertise in transfusion medicine, ASCT and clinical trials. The DSMB will convene after each group of 25 patients are enrolled or after 6 months, whichever comes first. Additional meetings/conferences calls will be conducted as necessary. The DSMB will use their experience in reviewing the data submitted to them. There will be no formal stopping rule; the DSMB will use their experience and expertise to advise the PATH Steering Committee on the prudence of stopping the trial early in case of safety concerns.

\section{Harms}

All participants are to be assessed for adverse events according to local institutional practice following standard ASCT except where additional assessment is required as per protocol. Source documentation of adverse events should be according to institutional practice, except in cases where additional information is required to be documented by the protocol. 


\section{Adverse events reporting}

Adverse events will be reported in the data collection forms on both study arms as follows:

1. Adverse event reporting should begin on the day 0 of ASCT.

2. All adverse events of grade 3 or greater and serious adverse events (SAEs) will be recorded up to platelet engraftment or day 30, whichever comes first.

3. The start date of each adverse event (that meets the criteria for recording) will be recorded in the 'adverse event data collection' form. The start date is defined as the date the adverse event first meets the criteria for grade 3 or greater. Stop dates do not need to be recorded unless the event is an SAE meeting the criteria for expedited reporting.

4. Abnormal laboratory results do not need to be recorded unless considered by the investigator to be relevant in terms of subject or trial safety (or in relation to an SAE, ie, being reported). CBCs (includes a white cell count, haemoglobin and platelet) are performed and reviewed during ASCT as part of routine clinical care. These values are expected to decrease as a direct consequence of the transplant procedure, which is unrelated to the red cell transfusion trigger. Consequently, we will not report any low white cell count, haemoglobin or platelet values as an adverse event, unless the decrease in these values is directly attributed to the tranexamic acid or platelet transfusion. We will document all platelet values as this is required to establish when a platelet transfusion should occur.

\section{Expedited SAE reporting}

Expedited SAE reporting are those that are deemed unexpected (not consistent with product information or labelling) and related/possibly related to the study intervention) will be faxed by the PATH Coordinating Centre to the Office of Clinical Trials, Health Canada using (1) adverse drug reactions (ADRs) for clinical trials expedited reporting summary form and (2) Council for International Organizations of Medical SciencesCIOMS form within the following timeframes:

1. Where it is neither fatal nor life threatening, within 15 days after becoming aware of the information;

2. Where it is fatal or life threatening, immediately where possible and, in any event, within 7 days after becoming aware of the information; and

3. Within 8 days after having informed Health Canada of the ADR, submit as complete a report as possible, which includes an assessment of the importance and implication of any findings (http://www.hc-sc.gc.ca/ dhp-mps/prodpharma/applic-demande/guide-ld/ clini/cta_post_approval-eng.php\#adr).

In the case of an expedited SAE, the PATH SAE form should be forwarded to the central coordinator as soon as possible after the site research coordinator learns of the event. Ideally, the Central Coordinating Centre should be apprised within 24 hours of the event. This requirement is applicable from the day of ASCT up to the end of study follow-up (either platelet engraftment or day 30 post-ASCT, whichever comes first).

All fields in the trial-specific SAE form will be completed. The local investigator will review, sign and with date the SAE form for confirmation of its accuracy. All Institutional Review Boards (IRB) engaged in the PATH study will be informed of expedited SAEs by the respective site coordinator (once the multicentre coordinator has informed the site). The multicentre coordinator may require further information from the site research team in order to complete the submission to Health Canada. Site research teams are requested to provide such requested information in a timely fashion.

The Study Chair and/or the Study Steering Committee will review all SAEs received from the sites. If an SAE is confirmed, a document summarising the SAE will be distributed to the participating sites. Sites will follow the guidelines of their local IRB with respect to the submission of SAEs that occur at the site as well as SAE notifications.

\section{Grading of adverse events}

The NCI Common Toxicity Criteria (CTCAE) V.4 will be used to grade adverse events that recipients experience. A copy of V.4 of the CTCAE is available from the CTEP home page (http://ctep.info.nih.gov).

\section{Reporting of deaths}

All deaths must be reported to the Project Management Office within 24 hours of the site's knowledge of the death. This requirement is applicable from the first day of HSCT to the end of study follow-up (day 30 post-ASCT). Death is considered a separate SAE from the SAE that precedes the death (ie, the SAE leading to the death). A separate death form must be completed in addition to the SAE form.

\section{Auditing}

The investigator must give the monitor access to relevant hospital or clinical records to confirm their consistency with the CRF entries. No information in these records about the identity of the patients will leave the study centre. Monitoring standards require verification of the presence of informed consent, adherence to the inclusion/exclusion criteria, documentation of all adverse events and outcomes required as per protocol. The investigator(s)/institution(s) will permit trial-related monitoring, audits, IRB review and regulatory inspections(s), providing direct access to source data/ documents.

\section{ETHICS AND DISSEMINATION}

\section{Research ethics approval}

This study will be undertaken at a site only after IRB has given full approval of the final protocol, amendments (if any), the informed consent form(s), applicable 
recruiting materials and the study management centre has received a copy of this approval. This approval letter must be dated and must clearly identify the documents being approved. The study management centre will require a copy of all IRB documents.

\section{Protocol amendments}

Any protocol amendments will be approved by the Steering Committee and communicated electronically to the site investigators and research staff. In turn, the amended protocol will be forwarded to respective site IRBs for review. Health Canada and the online trial registry will be accordingly updated.

\section{Consent or assent}

The recipient and/or the recipient's legally authorised guardian must acknowledge in writing (consent) to become a study participant on the PATH study. Consent will be obtained jointly by the most responsible healthcare provider (local investigator or co-investigator) and the local research coordinator.

\section{Confidentiality}

CRF will be faxed or mailed to the multicentre coordinator's office at registration and at follow-up time points. Data will be identified by an alphanumeric code only. Data will be entered (by staff at the multicentre coordinator's office or data management services) into the database. Importantly, source documentation will remain at their respective participating centre's site. The server for the database will be located in Ottawa Hospital Research Institute under the care of the Methods Centre. Appropriate security measures will be in place such that current Canadian privacy laws are adhered to with respect to security and confidentiality of data, electronic data transmission, data storage and data access. A secure ID and password will be necessary to access the system. Audit trails of entries will be provided. The project manager and the delegate will be the only individuals who can edit data. Records will be retained for a period of 25 years as per Health Canada regulations. After 25 years, all study records will be destroyed according to local policy. If the investigator withdraws from the responsibility of keeping the study records, custody must be transferred to a person willing to accept the responsibility.

Sites will track enrolment on a $\log$ where they will record the following information: patient name, hospital number, contact information, unique study number (randomisation number) and the study arm assigned. This $\log$ will be maintained at the site and will not be sent to the coordinating centre. The unique study number will be used to identify all CRFs (paper) from the site to the multicentre coordinator's office. The unique study number should be used for any other communication between the site and the multicentre coordinator's office.

\section{Declaration of interests}

The authors and investigators have no relevant conflicts of interests.

\section{Access to data}

Only the multicentre coordinator's office (and the delegate) will have authorisation to transfer data to the statistician for study analysis.

\section{Ancillary and post-trial care}

There will be no specific post-trial care, where medical care will follow local institutional practices. In the event of a study-related injury or illness, the participant will be provided with appropriate medical treatment and care. Financial compensation for lost wages, disability or discomfort due to an injury or illness will not be available. The legal rights of the participant will not be waived as a result of participation in the PATH. The investigators and their respective institutions will still have their legal and professional responsibilities.

\section{Dissemination policy}

Knowledge translation activities will take place throughout the duration of the study and will include clinical rounds, presentations, research team presentations at conferences and web-based disseminations. The project is registered with ClinicalTrials.gov. Scholarly articles will be submitted to relevant journals with open access publication. At the time or writing, there is no specific plan (s) to grant public access to the full protocol, participant-level data set or statistical code.

\section{ADMINISTRATIVE INFORMATION Steering Committee}

The interdisciplinary research team is composed of experienced researchers and clinicians with expertise in stem cell transplantation, psychology and QoL measures in transplant, transfusion medicine as well as clinical trials. The principal investigators and the co-investigators will serve as the Steering Committee. Independently and collectively the investigators have a wide range of expertise including transfusion medicine (AT, DM), transplantation (CB, DA, MS, DS, JT), malignant haematology (JT, DM, MS), clinical psychology and QoL (SB), clinical trials (AT, DF, JT, DM, KT, CB), epidemiology (DF, AT, JT, DM, KT, CB) and economic analyses (KT).

\section{Trial sponsor}

The PATH study is sponsored by the Ottawa Hospital Research Institute, 725 Parkdale Ave.

Ottawa, Ontario, Canada, K1Y 4E9.

\section{DISCUSSION}

Prophylactic platelet transfusions are commonly prescribed in patients undergoing ASCT to prevent bleeding based on daily measured platelet threshold (commonly $<10 \times 10^{9} / \mathrm{L}$ ). However, observational studies 
suggest that the platelet number does not correlate with clinical significant bleeding. Moreover, recent randomised studies suggest that prophylactic transfusions may not be necessary in patients receiving ASCT. However, ASCT clinicians remain uncomfortable not providing prophylactic platelets in the presence of thrombocytopenia. The PATH pilot study will 'bridge this gap' with the use of prophylactic tranexamic acid instead of prophylactic platelet transfusions.

There are several innovative features of the PATH pilot study design. First, investigations will remain blinded to the data collected in this pilot study. The data will be reviewed in aggregate by the investigators while unblinded data are available to the DSMB. In this way, the patients enrolled in this pilot study can be a part of the eventual sample size for the definitive phase III study. Second, the collection of patient-reported outcomes/QoL data is unique in clinical trials in platelet transfusions. Finally, we intend to engage patients and caregivers to better appreciate their preferences for a primary end point, in designing a phase III study.

Given the resource usage and high rate of adverse outcomes in HSCT, our study will provide the framework for better understanding the optimal use of platelet transfusions in patients receiving an ASCT. In this pilot study, we aim to determine the feasibility and logistics of conducting a multicentre trial and determine clinical outcome rates in order to plan and execute a prospective definitive randomised study.

Contributors All listed authors (JT, DA, SB, CB, DF, MS, DM, KT and AT) were equally involved in the design of the study and original grant submission to the Canadian Institute of Health Research. JT is the principal investigator involved in the protocol development, 'write-up' of this manuscript, execution and 'day-to-day' management of this study. Equal input was received from all other listed authors with respect to the above activities. All authors read and approved the final manuscript.

Funding Institute of Circulatory and Respiratory Health (RN260949_ 342593).

\section{Competing interests None declared}

Ethics approval Ottawa Health Science Network Research Ethics Board.

Provenance and peer review Not commissioned; externally peer reviewed.

Data sharing statement Knowledge translation activities will take place throughout the duration of the study and will include clinical rounds, presentations, research team presentations at conferences, and web-based disseminations. The project is registered with ClinicalTrials.gov. Scholarly articles will be submitted to relevant journals with open access publication.

Open Access This is an Open Access article distributed in accordance with the Creative Commons Attribution Non Commercial (CC BY-NC 4.0) license, which permits others to distribute, remix, adapt, build upon this work noncommercially, and license their derivative works on different terms, provided the original work is properly cited and the use is non-commercial. See: http:// creativecommons.org/licenses/by-nc/4.0/

\section{REFERENCES}

1. Estcourt L, Stanworth S, Doree C, et al. Prophylactic platelet transfusion for prevention of bleeding in patients with haematological disorders after chemotherapy and stem cell transplantation. Cochrane Database Syst Rev 2012;(5):CD004269.
2. Kaufman RM, Djulbegovic B, Gernsheimer T, et al. Platelet transfusion: a clinical practice guideline from the AABB. Ann Intern Med 2015;162:205-13.

3. Kumar A, Mhaskar R, Grossman BJ, et al. Platelet transfusion: a systematic review of the clinical evidence. Transfusion 2015;55:1116-27; quiz 15.

4. Nahirniak S, Slichter SJ, Tanael S, et al. Guidance on platelet transfusion for patients with hypoproliferative thrombocytopenia. Transfus Med Rev 2015;29:3-13.

5. Christou G, Kekre N, Petrcich W, et al. Impact of platelet transfusion on toxicity and mortality after hematopoietic progenitor cell transplantation. Transfusion 2015;55:253-8.

6. Stanworth SJ, Estcourt LJ, Powter G, et al. A no-prophylaxis platelet-transfusion strategy for hematologic cancers. N Engl J Med 2013;368:1771-80.

7. Wandt $\mathrm{H}$, Schaefer-Eckart $\mathrm{K}$, Frank $\mathrm{M}$, et al. A therapeutic platelet transfusion strategy is safe and feasible in patients after autologous peripheral blood stem cell transplantation. Bone Marrow Transplant 2006;37:387-92.

8. Wandt $\mathrm{H}$, Schaefer-Eckart $\mathrm{K}$, Wendelin $\mathrm{K}$, et al. Therapeutic platelet transfusion versus routine prophylactic transfusion in patients with haematological malignancies: an open-label, multicentre, randomised study. Lancet 2012;380:1309-16.

9. Callum JL, Lin Y, Pinkerton PH, et al. Bloody easy 3: blood transfusions, blood alternatives and transfusion reactions, a guide to transfusion medicine. 3rd edn. Orbcon, 2011.

10. Galel SA. Infectious disease screening AABB technical manual. 18th edn. 2014:179-206

11. Lin Y, Callum JL, Pinkerton PH. Adverse reactions. 2011 edn. Clinical Guide To Transfusion, 2013.

12. Mazzei CA, Popovsky M, Kopko PM. Noninfectious complications of blood transfusion. In: Fung MK, Grossman BJ, Hillyer C, Westhoff CM, eds. Technical Manual, 18th edition, 2014:665-92. http:// marketplace.aabb.org/EbusPPROD/Default.aspx? TablD $=55$ \& productld $=2042730$

13. Wardrop D, Estcourt LJ, Brunskill SJ, et al. Antifibrinolytics (lysine analogues) for the prevention of bleeding in patients with haematological disorders. Cochrane Database Syst Rev 2013;(7): CD009733.

14. Avvisati G, ten Cate JW, Büller HR, et al. Tranexamic acid for control of haemorrhage in acute promyelocytic leukaemia. Lancet 1989;2:122-4. https://www.ncbi.nlm.nih.gov/pubmed/23897323

15. Shpilberg O, Blumenthal R, Sofer O, et al. A controlled trial of tranexamic acid therapy for the reduction of bleeding during treatment of acute myeloid leukemia. Leuk Lymphoma 1995; 19:141-4.

16. Stanworth SJ, Estcourt LJ, Llewelyn CA, et al. Impact of prophylactic platelet transfusions on bleeding events in patients with hematologic malignancies: a subgroup analysis of a randomized trial. Transfusion 2014:54:2385-93.

17. Heddle NM, Cook RJ, Tinmouth A, et al. A randomized controlled trial comparing standard- and low-dose strategies for transfusion of platelets (STOP) to patients with thrombocytopenia. Blood 2009;113:1564-73.

18. Slichter SJ, Kaufman RM, Assmann SF, et al. Dose of prophylactic platelet transfusions and prevention of hemorrhage. N Engl J Med 2010;362:600-13.

19. Tinmouth A, Tannock IF, Crump M, et al. Low-dose prophylactic platelet transfusions in recipients of an autologous peripheral blood progenitor cell transplant and patients with acute leukemia: a randomized controlled trial with a sequential Bayesian design. Transfusion 2004;44:1711-19.

20. Sensebé L, Giraudeau B, Bardiaux L, et al. The efficiency of transfusing high doses of platelets in hematologic patients with thrombocytopenia: results of a prospective, randomized, open, blinded end point (PROBE) study. Blood 2005;105: 862-4.

21. Gaydos LA, Freireich EJ, Mantel N. The quantitative relation between platelet count and hemorrhage in patients with acute leukemia. N Engl J Med 1962;266:905-9.

22. Friedmann AM, Sengul H, Lehmann $\mathrm{H}$, et al. Do basic laboratory tests or clinical observations predict bleeding in thrombocytopenic oncology patients? A reevaluation of prophylactic platelet transfusions. Transfus Med Rev 2002;16:34-45.

23. Bernstein SH, Nademanee AP, Vose JM, et al. A multicenter study of platelet recovery and utilization in patients after myeloablative therapy and hematopoietic stem cell transplantation. Blood 1998;91:3509-17.

24. Stanworth SJ, Hyde C, Brunskill S, et al. Platelet transfusion prophylaxis for patients with haematological malignancies: where to now? Br J Haematol 2005;131:588-95. 
25. Schiffer CA, Anderson KC, Bennett CL, et al. Platelet transfusion for patients with cancer: clinical practice guidelines of the American Society of Clinical Oncology. J Clin Oncol 2001;19:1519-38.

26. Higby DJ, Cohen E, Holland JF, et al. The prophylactic treatment of thrombocytopenic leukemic patients with platelets: a double blind study. Transfusion 1974;14:440-6.

27. Murphy S, Litwin S, Herring LM, et al. Indications for platelet transfusion in children with acute leukemia. Am J Hematol 1982;12:347-56.

28. Solomon J, Bofenkamp T, Fahey JL, et al. Platelet prophylaxis in acute non-lymphoblastic leukaemia. Lancet 1978;1:267.

29. Blumberg N, Heal JM, Liesveld JL, et al. Platelet transfusion and survival in adults with acute leukemia. Leukemia 2008;22:631-5.

30. Eftekharian $\mathrm{H}$, Vahedi R, Karagah $\mathrm{T}$, et al. Effect of tranexamic acid irrigation on perioperative blood loss during orthognathic surgery: a double-blind, randomized controlled clinical trial. J Oral Maxillofac Surg 2015;73:129-33.

31. Karaaslan F, Karaoğlu S, Mermerkaya MU, et al. Reducing blood loss in simultaneous bilateral total knee arthroplasty: combined intravenous-intra-articular tranexamic acid administration.

A prospective randomized controlled trial. Knee 2015;22:131-5.

32. Mirghafourvand M, Mohammad-Alizadeh S, Abbasalizadeh F, et al. The effect of prophylactic intravenous tranexamic acid on blood loss after vaginal delivery in women at low risk of postpartum haemorrhage: a double-blind randomised controlled trial. Aust $N Z$ J Obstet Gynaecol 2015;55:53-8.

33. Roberts I, Coats T, Edwards P, et al. HALT-IT-tranexamic acid for the treatment of gastrointestinal bleeding: study protocol for a randomised controlled trial. Trials 2014;15:450.

34. Sprigg N, Renton CJ, Dineen RA, et al. Tranexamic acid for spontaneous intracerebral hemorrhage: a randomized controlled pilot trial (ISRCTN50867461). J Stroke Cerebrovasc Dis 2014;23:1312-18.

35. Zehtabchi S, Abdel Baki SG, Falzon L, et al. Tranexamic acid for traumatic brain injury: a systematic review and meta-analysis. Am J Emerg Med 2014;32:1503-9.

36. National Heart Lung and Blood Institute. The diagnosis, evaluation, and management of von Willebrand disease. NIH publication no 08-5832. Bethesda, MD: U.S. Dept. of Health and Human Services, National Institutes of Health, National Heart, Lung, and Blood Institute, 2007.

37. Srivastava A, Brewer AK, Mauser-Bunschoten EP, et al. Guidelines for the management of hemophilia. Haemophilia 2013;19:e1-47.
38. World Health Organization. WHO handbook for reporting results of cancer treatment. Geneva: World Health Organization, 1979.

39. Bercovitz RS, O'Brien SH. Measuring bleeding as an outcome in clinical trials of prophylactic platelet transfusions. Hematology Am Soc Hematol Educ Program 2012;2012:157-60.

40. Koreth R, Weinert C, Weisdorf DJ, et al. Measurement of bleeding severity: a critical review. Transfusion 2004:44:605-17.

41. Estcourt LJ, Heddle N, Kaufman R, et al. The challenges of measuring bleeding outcomes in clinical trials of platelet transfusions. Transfusion 2013;53:1531-43.

42. Webert K, Cook RJ, Sigouin CS, et al. The risk of bleeding in thrombocytopenic patients with acute myeloid leukemia. Haematologica 2006;91:1530-7.

43. Webert KE, Arnold DM, Lui Y, et al. A new tool to assess bleeding severity in patients with chemotherapy-induced thrombocytopenia. Transfusion 2012;52:2466-74; quiz 65.

44. Estcourt LJ, Pinchon D, Symington E, et al. Does bleeding affect patient-reported outcome measures in patients with myelodysplasia or hematologic malignancies: a systematic review. Transfusion 2014;54:1166-79.

45. Heddle NM, Arnold DM, Webert KE. Time to rethink clinically important outcomes in platelet transfusion trials. Transfusion 2011;51:430-4.

46. Rabin R, de Charro F. EQ-5D: a measure of health status from the EuroQol Group. Ann Med 2001;33:337-43.

47. Cella D, Beaumont JL, Webster KA, et al. Measuring the concerns of cancer patients with low platelet counts: the Functional Assessment of Cancer Therapy-thrombocytopenia (FACT-Th) questionnaire. Support Care Cancer 2006:14:1220-31.

48. Patient-Centered Outcomes Research Institute. 2015. http://www pcori.org/ (accessed 05 Nov 2015).

49. Bearman SI, Appelbaum FR, Buckner CD, et al. Regimen-related toxicity in patients undergoing bone marrow transplantation. $J$ Clin Oncol 1988:6:1562-8

50. McQuellon RP, Russell GB, Cella DF, et al. Quality of life measurement in bone marrow transplantation: development of the Functional Assessment of Cancer Therapy-Bone Marrow Transplant (FACT-BMT) scale. Bone Marrow Transplant 1997;19:357-68.

51. Spitzer RL, Kroenke K, Williams JB, et al. A brief measure for assessing generalized anxiety disorder: the GAD-7. Arch Intern Med 2006;166:1092-7.

52. Cook RJ, Heddle NM, Rebulla $P$, et al. Methods for the analysis of bleeding outcomes in randomized trials of PLT transfusion triggers. Transfusion 2004;44:1135-42. 